small facial mass. Clinical findings included a small triangular face with frontal bossing, blue sclerae, thin lips with downturned corners, retromicrognathia, and limb asymmetry. Weight and height at admission were less than 5th percentile (Weight was $3.9 \mathrm{~kg}$ and size $56 \mathrm{~cm}$ ); her head circumference grew normally along the 75 th percentile.

Observation 2 A male Infant was hospitalised at the age of 1 year and 4 months. Physical examination showed growth deficiency: Weight: $7.1 \mathrm{Kg}$ (<5th percentile), size: $72 \mathrm{~cm}$, head cirumference: $46 \mathrm{~cm}$ (25th percentile). The same facial features as the first case was found with body asymmetry, flat and narrow feet and cryptorchidism.

Conclusion The diagnosis of this syndrome is based on clinical findings. The treatment is purely symptomatic and growth hormone administration does not achieve the target size. The longterm prognosis, a part the growth, is good.

\section{PO-0363 ASKIN TUMOUR:CASE REPORT}

S Hammami, H Besbès, A Mnari, CH Ben Meriem, S Hadded, MN Guédiche. Pediatric, Fattouma Bourguiba Hospital, Monastir, Tunisia

\subsection{6/archdischild-2014-307384.1011}

Introduction Askin tumour is a primitive neuroectodermal tumour of the thoracopulmonary region. Pulmonary location is not common. We report a case of an Askin tumour in a child who presented with worsening breathlessness.

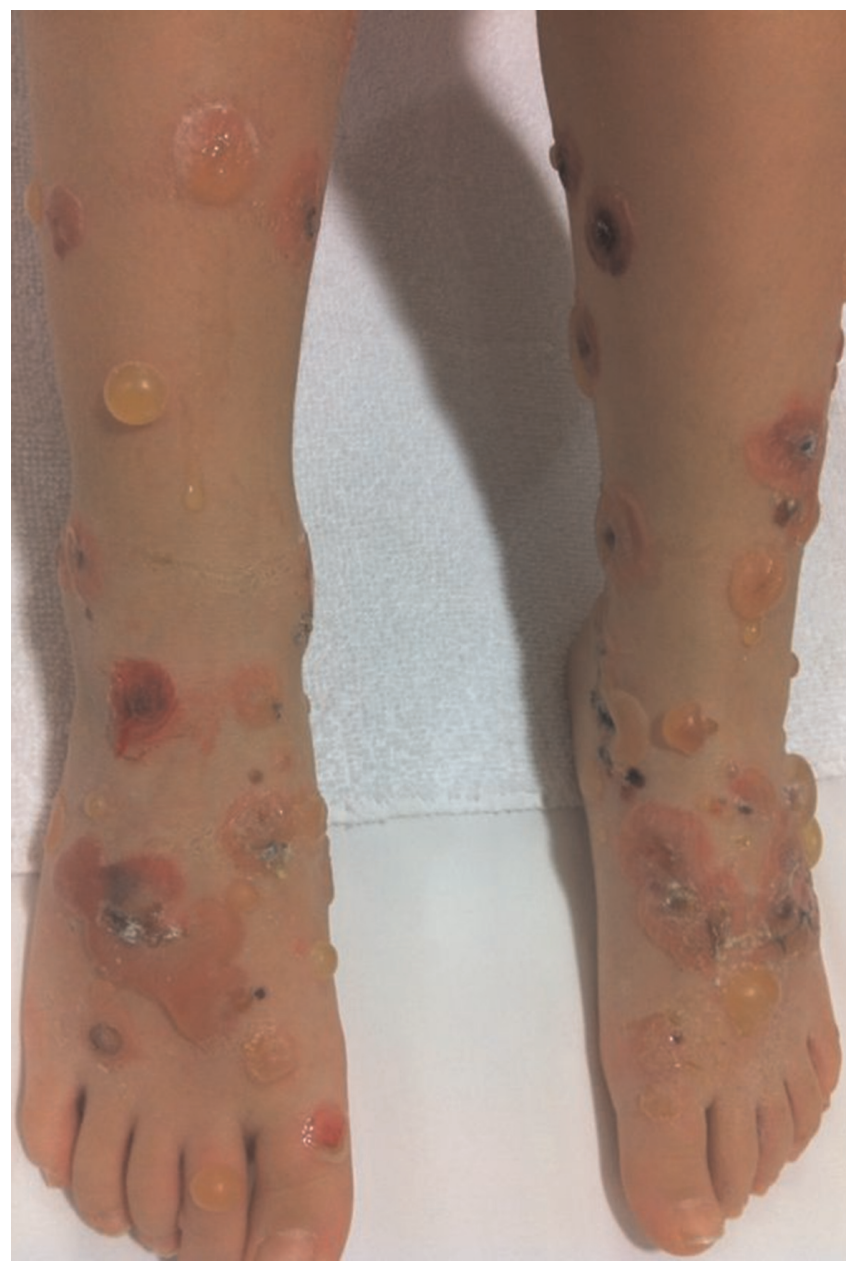

Observation A 9 years-old female child with no pathological history, was admitted with severe dyspnea up to one week. A Weight loss was reported. Physical examination showed silence in pulmonary auscultation of the left lung field. A chest X-ray found a left opacity occupying almost the entire of the left lung, mediastinal compression to the right side and nibbled aspect of the fourth rib. Chest Ultrasound showed pleural effusion with finely heterogeneous liquid. Chest CT showed a pulmonary solid tumour with aspect of massive necrosis of the left upper lobe with hemothorax, rib erosion in contact, without lymphadenopathy or vascular invasion or secondary lesion distance. A scanoguided biopsy was performed and immuno-histological examination found a small round cell tumour with morphological aspects favour the diagnosis of primitive peripheral neuroectodermal tumour corresponding to an Askin tumour. The child underwent an intensive chemotherapy and surgery.

Conclusion The management of Askin tumour is not well codified. The prognosis of these tumours remains very unfavourable because of their metastatic risk and potential local recurrence.

\section{PO-0364 HISTOLOGICAL ASPECTS OF THE FETO-PLACENTAL INTERFACE IN THE PREGNANCY INDUCED HYPERTENSION}

${ }^{1} \mathrm{R}$ \|lie, ${ }^{2} \mathrm{C}$ llie, ${ }^{2} \mathrm{~F}$ Capitan, ${ }^{2} \mathrm{~A}$ Nyiredi, ${ }^{2}$ Enatescu. ${ }^{1}$ Pathology, Emergency Children's Hospital Louis Turcanu, Timisoara, Romania; ${ }^{2}$ Neonatology, Victor Babes University of Medicine and Pharmacy, Timisoara, Romania

\subsection{6/archdischild-2014-307384.1012}

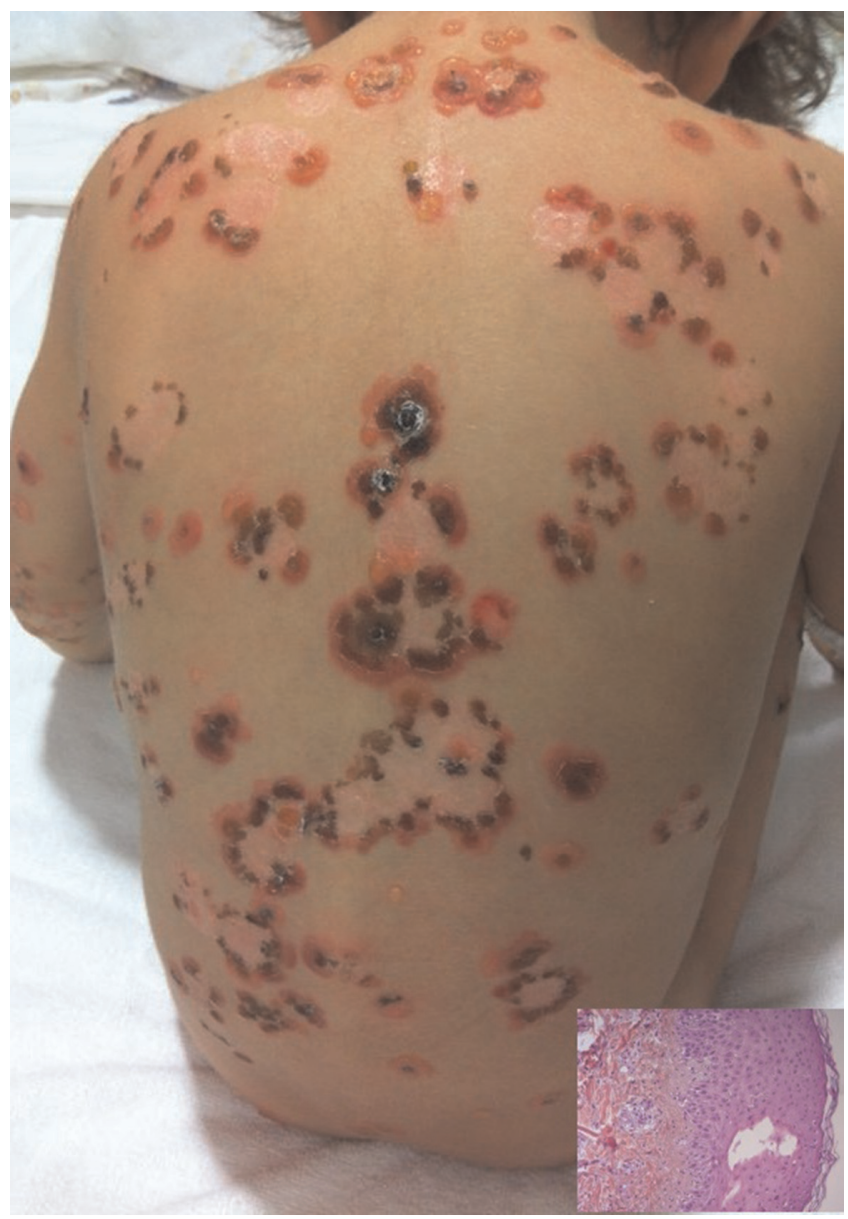

Abstract P0-0354 Figure 2 